\title{
ANALISIS PEMELIHARAAN MESIN PEMBUAT TAHU (STUDI PADA PABRIK TAHU MITRA CEMANGI DI KOTA PALU)
}

\author{
Nurhasana S. Pau \\ Asngadi \\ Program Studi S1 Manajemen Fakultas Ekonomi Universitas Tadulako \\ email: nurhasana.s.pau98@gmail.com
}

\begin{abstract}
This study aims to determine and analyze the level of efficiency of preventive and corrective maintenance policies and to find out whether the policies implemented are efficient. This research was conducted by interview and direct observation in the tofu factory Mitra Cemangi Palu City. The method used is descriptive quantitative. The results showed that preventive maintenance for steam boilers per year about Rp.540,514, and milled machines for bearing components about Rp.377,225, dynamos Rp.4,452,883, milled stones Rp.538,197 and v-belts about Rp.84,927,- while the corrective cost for the boiler about Rp.1,000,000 and the milling machine for bearing components is Rp.209,580, the dynamo is Rp.4,504,505, the stone is Rp.800,000 and the v-belt about Rp.35,000. Difference in maintenance costs obtained from the two types of machines are more efficient using preventive maintenance than corrective.
\end{abstract}

Keywords : Maintenance, Preventive, Corrective, and Cost Efficiency

\begin{abstract}
Abstrak
Penelitian ini bertujuan untuk mengetahui dan menganalisis tingkat efisiensi dari kebijakan pemeliharaan preventive dan corrective serta untuk mengetahui apakah kebijakan yang diterapkan sudah efisien. Penelitian ini dilakukan dengan cara wawancara dan observasi langsung di pabrik tahu Mitra Cemangi Kota Palu. Metode yang digunakan yaitu deskriptif kuantitatif. Hasil penelitian menunjukkan bahwa pemeliharaan preventif untuk mesin ketel uap pertahun sebesar Rp.540.514,- dan mesin giling untuk komponen laher sebesar Rp.377.225, dinamo Rp.4.452.883, batu giling Rp.538.197 dan v-belt sebesar Rp.84.927,- sedangkan biaya korektif untuk mesin ketel uap yaitu sebesar Rp.1.000.000,- dan mesin giling untuk komponen laher sebesar Rp.209.580, dinamo Rp.4.504.505, batu giling Rp.800.000 dan v-belt sebesar Rp.35.000,-. Selisih biaya pemeliharaan yang diperoleh dari kedua jenis mesin lebih efisien menggunakan pemeliharaan preventif daripada korektif.
\end{abstract}

Kata Kunci : Pemeliharaan, Preventive, Corrective, dan Efisiensi Biaya

\section{PENDAhULUAN}

Pada masa sekarang dengan berbagai kecanggihan teknologi yang ada, Usaha Mikro Kecil dan Menengah (UMKM) dituntut untuk dapat menciptakan suatu inovasi dalam dunia usaha, karena UMKM mempunyai peranan yang sangat penting dalam memajukan pertumbuhan perekonomian Indonesia. Oleh karena itu, suatu perusahaan yang melakukan bisnis atau usaha sangat dituntut untuk dapat menciptakan keunggulan bersaingnya sehingga perusahaan tersebut dapat bersaing baik dalam skala nasional maupun skala global, sehingga perlu melakukan penyesuaian terhadap teknologi untuk membantu kinerja suatu perusahaan khususnya perusahaan yang bergerak dibidang industri manufaktur.

Industri manufaktur adalah sebuah industri kegiatan manusia yang bertujuan untuk mendesain atau mengubah bahan baku menjadi output yang kemudian siap untuk dijual dan dipasarkan kepada para konsumen (Asngadi, 2011). Salah satu faktor penunjang keberhasilan dari sebuah perusahaan manufaktur adalah ketersediaan mesin, dan peralatan atau fasilitas yang memadai. 
Pabrik Tahu Mitra Cemangi adalah sebuah usaha yang melakukan kegiatan produksi menggunakan mesin yang cukup sederhana dan sebagian kegiatan produksinya masih manual dan belum menggunakan mesin, sehingga masih terdapat kerusakan-kerusakan mesin di pabrik tersebut, akibat kurangnya pemeliharaan pada mesin. Hal tersebut juga yang membuat umur ekonomis mesin tidak bertahan lama pada saat digunakan dalam kegiatan produksi.

Pabrik tahu Mitra Cemangi sendiri sangat menyadari sepenuhnya bahwa pemeliharaan mesin haruslah dilakukan secara teratur dan rutin, seperti mengganti bagian-bagian pada mesin yang rusak dan sudah waktunya harus diganti, serta memperhatikan biaya-biaya yang harus dikeluarkan untuk melakukan pemeliharaan mesin pabrik khususnya pemeliharaan pada mesin yang menjadi jantung dari kegiatan proses produksi yaitu ketel uap (Boiler) yang terdiri atas 2 unit (aktif digunakan 1 unit), dan mesin giling 2 unit (aktif digunakan 1 unit).

Mesin-mesin yang digunakan serta tahun perolehan mesin di pabrik tahu Mitra Cemangi Kota Palu adalah sebagai berikut:

Tabel 1

Daftar Mesin yang digunakan serta Tahun Perolehan Mesin di Pabrik Tahu Mitra Cemangi Kota Palu (2018)

\begin{tabular}{lccccc}
\hline No. & Nama Mesin & $\begin{array}{c}\text { Jumlah Mesin } \\
\text { Aktif digunakan } \\
\text { (unit) }\end{array}$ & $\begin{array}{c}\text { Tahun } \\
\text { Perolehan }\end{array}$ & $\begin{array}{c}\text { Harga } \\
\text { (Rp) }\end{array}$ & $\begin{array}{c}\text { Umur } \\
\text { Ekonomis }\end{array}$ \\
\hline 1. & Ketel Uap & 1 & 2007 & 30.000 .000 & 2 Tahun \\
2. & Mesin Giling & 1 & 2015 & 3.500 .000 & 5 Tahun \\
& Total & 2 & & Rp.33.500.000 ,- & \\
\hline
\end{tabular}

Sumber: Pabrik Tahu Mitra Cemangi

Kerusakan mesin pabrik tahu Mitra Cemangi Kota Palu adalah jenis kerusakan yang terjadi pada waktu-waktu tertentu untuk setiap mesinnya, Adapun cadangan sparepart untuk mesin yang mengalami kerusakan penyediaannya masih sangat minim sehingga apabila mesin tersebut rusak maka penggantian sparepart dan perbaikan pada mesin tidak dapat dilakukan secara langsung. Berikut adalah kerusakan-kerusakan mesin produksi pabrik tahun 2018 adalah sebagai berikut:

Tabel 2

Kerusakan Mesin-Mesin Produksi Pabrik Tahun 2018

\begin{tabular}{|c|c|c|c|c|c|}
\hline No. & Mesin & $\begin{array}{c}\text { Jenis Kerusakan } \\
\text { Mesin }\end{array}$ & $\begin{array}{l}\text { Frekuensi } \\
\text { Kerusakan }\end{array}$ & $\begin{array}{c}\text { Biaya } \\
\text { Kerusakan/Tahun }\end{array}$ & $\begin{array}{c}\text { Anggaran } \\
\text { Kerusakan }\end{array}$ \\
\hline 1. & $\begin{array}{l}\text { Ketel } \\
\text { Uap }\end{array}$ & $\begin{array}{l}\text { Pompa air rusak } \\
\text { sehingga ketel } \\
\text { mengalami } \\
\text { kebocoran. }\end{array}$ & 1 kali & Rp.8.000.000,- & Rp. 10.000 .000 \\
\hline 2. & $\begin{array}{l}\text { Mesin } \\
\text { Giling }\end{array}$ & \begin{tabular}{l} 
laher dan dinamo \\
rusak, Batu giling \\
rusak terkikis \\
karena gesekan \\
pada saat \\
penggilingan, \\
serta $V$-Belt pada \\
mesin kendor. \\
\multicolumn{1}{c}{ Total }
\end{tabular} & 12 kali & Rp.23.940.000,- & Rp.24.000.000 \\
\hline
\end{tabular}

Sumber: Pabrik Tahu Mitra Cemangi

Berdasarkan hasil wawancara peneliti bersama pemilik dan karyawan pabrik tahu Mitra Cemangi, bahwa mesin biasanya mengalami trouble karena kurangnya pemeliharaan atau 
perawatan terhadap mesin, karena pada umumnya pihak pabrik tahu Mitra Cemangi lebih dominan melakukan perawatan korektif (perbaikan).

Pabrik tahu Mitra Cemangi sendiri telah mengeluarkan banyak biaya terhadap pemeliharaan mesinnya sehingga perlu adanya efisiensi biaya yang tepat terhadap penggunaan sistem pemeliharaan agar dapat memperkecil pengeluaran biaya. Hal tersebut sesuai dengan riset yang dilakukan oleh (Ruftyaz, 2017) dan (Putra I, 2018) yang mengemukakan bahwa Efisiensi biaya pemeliharaan suatu perusahaan sangat dibutuhkan agar dapat memperkecil pengeluaran biaya.

Berdasarkan permasalahan dan data hasil penelitian tersebut di atas, maka peneliti tertarik untuk mengambil judul "Analisis Pemeliharaan Mesin Pembuat Tahu" (Studi Pada Pabrik Tahu Mitra Cemangi di Kota Palu).

\section{KAJIAN LITERATURE}

\section{Pengertian Manajemen Produksi dan Manajemen Operasi}

Kegiatan produksi dan operasi merupakan suatu kegiatan manufaktur untuk mengelola bahan baku, bahan setengah jadi sampai barang jadi untuk menghasilkan suatu output sesuai standar yang ditentukan sehingga menghasilkan keuntungan bagi perusahaan. Pengertian manajemen operasi menurut Render dan Heizer (2012) manajemen operasi (operation management-OM) adalah serangkaian aktivitas yang menghasilkan nilai dalam bentuk barang dan jasa dengan mengubah input menjadi output.

Manajemen produksi adalah suatu ilmu yang membahas secara komprehensif bagaimana pihak manajemen produksi perusahaan mempergunakan ilmu dan seni yang dimiliki dengan mengarahkan dan mengatur orang-orang untuk mencapai suatu hasil produksi yang diinginkan (Fahmi, 2014:3).

\section{Pengertian Pemeliharaan Mesin}

Menurut Assauri (1980:88), "pemeliharaan adalah kegiatan untuk memelihara atau menjaga fasilitas atau peralatan pabrik dan mengadakan perbaikan atau penyesuaian, penggantian yang diperlukan agar supaya terdapat suatu keadaan operasi produksi yang memuaskan sesuai dengan apa yang direncanakan".

\section{Fungsi Pemeliharaan}

Menurut Ahyari (2002) fungsi pemeliharaan adalah agar dapat memperpanjang umur ekonomis dari mesin dan peralatan produksi yang ada serta mengusahakan agar mesin dan peralatan produksi tersebut selalu dalam keadaan optimal dan siap pakai untuk pelaksanaan proses produksi”.

\section{Tujuan Pemeliharaan}

Menurut Daryus (2008) dalam bukunya Manajemen Pemeliharaan Mesin, tujuan pemeliharaan yang utama dapat di definisikan sebagai berikut:

1. Untuk memperpanjang kegunaan aset.

2. Untuk menjamin ketersediaan optimum peralatan yang dipasang untuk produksi dan mendapatkan laba investasi maksimum.

3. Untuk menjamin kesiapan operasional dari seluruh peralatan yang diperlukan dalam keadaan darurat setiap waktu.

4. Untuk menjamin keselamatan orang yang menggunakan sarana tersebut.

\section{Jenis-Jenis Pemeliharaan}

Menurut Assauri (2008:135) jenis pemeliharaan terbagi menjadi dua yaitu: 
1. Preventive Maintenance adalah kegiatan pemeliharaan dan perawatan yang dilakukan untuk mencegah timbulnya kerusakan-kerusakan yang tidak terduga dan menemukan kondisi atau keadaan yang dapat menyebabkan fasilitas produksi mengalami kerusakan pada waktu digunakan dalam proses produksi.

2. Corrective atau Breakdown Maintenance Kegiatan pemeliharaan dan perawatan ini dilakukan setelah terjadinya suatu kerusakan atau kelainan pada fasilitas atau peralatan sehingga tidak dapat berfungsi dengan baik. Kegiatan corrective maintenance yang dilakukan sering disebut dengan kegiatan perbaikan atau reparasi.

\section{Sistem dan Peran Pemeliharaan}

Menurut Jhons dan Harding (1996). Pengembangan suatu strategi pemeliharaan melibatkan suatu rangkaian keputusan struktural antara lain (1) aset apa yang harus dipelihara, (2) bagaimana atau atas dasar apa aset harus dipelihara, (3) kapan atau seberapa sering aset harus dipelihara, (4) siapa yang harus mengerjakan dan keterampilan apa yang dibutuhkan.

\section{Strategi Pemeliharaan Mesin}

Menurut Prawirosentono (2007) strategi perawatan dapat dibagi menjadi berikut ini:

a. Strategi perawatan berencana

b. Strategi perawatan pencegahan

c. Strategi perawatan peramalan

d. Strategi perawatan darurat

e. Strategi pengukuran kerja para tenaga perawat mesin.

\section{Menyusun Rencana Pemeliharaan Secara Sistematis}

Menurut Prawirosentono (2007) tentang penyusunan rencana pemeliharaan secara sistematis dapat dibagi sebagai berikut:

a. Merencanakan pemeliharaan yang efektif

b. Perintah kerja (working order)

c. Melaksanakan perawatan/pemeliharaan

\section{Pengertian Efisiensi}

Efisiensi merupakan suatu ukuran keberhasilan yang dinilai dari segi besarnya sumber/biaya untuk mencapai hasil dari kegiatan yang dijalankan. (Rusdiana, 2000:20).

\section{METODE PENELITIAN}

Jenis penelitian ini adalah penelitian deskriptif kuantitatif yaitu suatu data yang diperoleh peneliti dari hasil penelitian yang dianalisis sesuai dengan metode statistik yang digunakan kemudian di jabarkan. Adapun data yang dibutuhkan yaitu data kerusakan mesin, kapasitas mesin, dan biaya pemeliharaan.

Penelitian ini bertempat di pabrik tahu Mitra Cemangi Kota Palu, beralamat di Jalan Cemangi, No.9 Kelurahan Duyu Kecamatan Tatanga Kota Palu Sulawesi Tengah.

Populasi adalah semua pihak yang terkait dengan penelitian ini. Populasi dalam penelitian ini yaitu seluruh mesin yang terlibat dalam proses produksi dipabrik tahu Mitra Cemangi Kota Palu, yang terdiri dari dua mesin yaitu mesin ketel uap dan mesin giling. Informan adalah responden yang dapat memberikan informasi yang dibutuhkan oleh peneliti. Informan kunci adalah orang yang mengetahui secara mendalam tentang permasalahan dari peneliti. Informan kunci dalam penelitian ini adalah semua pihak yang dianggap bisa menjawab atau mewakili untuk memberikan informasi yang diperlukan yaitu pemilik atau karyawan pabrik. Sistem penarikan sampel dilakukan dengan menggunakan non probability sampling yaitu sampling jenuh (sensus). Sampling jenuh adalah penentuan sampel bila semua anggota populasi digunakan sebagai sampel. Sampel dalam penelitian ini adalah mesin ketel uap frekuensi kerusakan sebanyak 1 kali dalam setahun dengan 
biaya pemeliharaan preventif sebesar Rp.540.514 dan biaya pemeliharaan korektif sebesar Rp.1.000.000, dan mesin giling frekuensi kerusakannya terjadi sebanyak 12 kali dalam setahun dengan biaya pemeliharaan preventif untuk komponen laher sebesar Rp.377.225, dinamo sebesar Rp.4.452.883, batu giling sebesar Rp.538.197 dan V-Belt sebesar Rp.84.927. Sedangkan untuk biaya pemeliharaan korektif untuk komponen laher adalah sebesar Rp.209.580, untuk dinamo sebesar Rp.4.504.505, batu giling sebesar Rp.800.000 dan V-Belt yaitu sebesar Rp.35.000.

Metode deskriptif kuantitatif adalah suatu bentuk analisis data dengan menggunakan statistik dan matematik sebagai alat untuk memperoleh sistem pemeliharaan, untuk membantu memutuskan kebijakan pemeliharaan yang akan diambil pada suatu jangka waktu tertentu. Handoko (2014:163) merumuskan kebijakan pemeliharaan sebagai berikut:

1. Pemeliharaan pencegahan selama 12 bulan:

1. Pemeliharaan pencegahan setiap sebulan sekali, $\mathrm{B}_{1}=\mathrm{NP}_{1}$

2. Pemeliharaan pencegahan setiap dua bulan sekali, $\mathrm{B}_{2}=\mathrm{N}\left(\mathrm{P}_{1}+\mathrm{P}_{2}\right)+\mathrm{B}_{1} \mathrm{P}_{1}$

3. Pemeliharaan pencegahan setiap tiga bulan sekali, $\mathrm{B}_{3}=\mathrm{N}\left(\mathrm{P}_{1}+\mathrm{P}_{2}+\mathrm{P}_{3}\right)+\mathrm{B}_{2} \mathrm{P}_{1}+\mathrm{B}_{1} \mathrm{P}_{2}$

4. Pemeliharaan pencegahan setiap empat bulan sekali, $\mathrm{B}_{4}=\mathrm{N}\left(\mathrm{P}_{1}+\mathrm{P}_{2}+\mathrm{P}_{3}+\mathrm{P}_{4}\right)+\mathrm{B}_{3} \mathrm{P}_{1}+\mathrm{B}_{2} \mathrm{P}_{2}+\mathrm{B}_{1} \mathrm{P}_{3}$

5. Pemeliharaan pencegahan setiap lima bulan sekali, $\mathrm{B}_{5}=\mathrm{N}\left(\mathrm{P}_{1}+\ldots+\mathrm{P}_{5}\right)+\mathrm{B}_{4} \mathrm{P}_{1}+\mathrm{B}_{3} \mathrm{P}_{2}+\mathrm{B}_{2} \mathrm{P}_{3}+\mathrm{B}_{1} \mathrm{P}_{4}$

6. Pemeliharaan pencegahan setiap enam bulan sekali, $\mathrm{B}_{6}=\mathrm{N}\left(\mathrm{P}_{1}+\ldots+\mathrm{P}_{6}\right)+\mathrm{B}_{5} \mathrm{P}_{1}+\mathrm{B}_{4} \mathrm{P}_{2}+\mathrm{B}_{3} \mathrm{P}_{3}+\mathrm{B}_{2} \mathrm{P}_{4}+\mathrm{B}_{1} \mathrm{P}_{5}$

7. Pemeliharaan pencegahan setiap tujuh bulan sekali, $\mathrm{B}_{7}=\mathrm{N}\left(\mathrm{P}_{1}+\ldots+\mathrm{P}_{7}\right)+\mathrm{B}_{6} \mathrm{P}_{1}+\mathrm{B}_{5} \mathrm{P}_{2}+\mathrm{B}_{4} \mathrm{P}_{3}+\mathrm{B}_{3} \mathrm{P}_{4}+\mathrm{B}_{2} \mathrm{P}_{5}+\mathrm{B}_{1} \mathrm{P}_{6}$

8. Pemeliharaan pencegahan setiap delapan bulan sekali, $\mathrm{B}_{8}=\mathrm{N}\left(\mathrm{P}_{1}+\ldots+\mathrm{P}_{8}\right)+\mathrm{B}_{7} \mathrm{P}_{1}+\mathrm{B}_{6} \mathrm{P}_{2}+\mathrm{B}_{5} \mathrm{P}_{3}+\mathrm{B}_{4} \mathrm{P}_{4}+\mathrm{B}_{3} \mathrm{P}_{5}+\mathrm{B}_{2} \mathrm{P}_{6}+\mathrm{B}_{1} \mathrm{P}_{7}$

9. Pemeliharaan pencegahan setiap Sembilan bulan sekali, $\mathrm{B}_{9}=\mathrm{N}\left(\mathrm{P}_{1}+\ldots+\mathrm{P}_{9}\right)+\mathrm{B}_{8} \mathrm{P}_{1}+\mathrm{B}_{7} \mathrm{P}_{2}+\mathrm{B}_{6} \mathrm{P}_{3}+\mathrm{B}_{5} \mathrm{P}_{4}+\mathrm{B}_{4} \mathrm{P}_{5}+\mathrm{B}_{3} \mathrm{P}_{6}+$ $\mathrm{B}_{2} \mathrm{P}_{7}+\mathrm{B}_{1} \mathrm{P}_{8}$

10. Pemeliharaan pencegahan setiap sepuluh bulan sekali, $\mathrm{B}_{10}=\mathrm{N}\left(\mathrm{P}_{1}+\ldots+\mathrm{P}_{10}\right)+\mathrm{B}_{9} \mathrm{P}_{1}+\mathrm{B}_{8} \mathrm{P}_{2}+\mathrm{B}_{7} \mathrm{P}_{3}+\mathrm{B}_{6} \mathrm{P}_{4}+\mathrm{B}_{5} \mathrm{P}_{5}+\mathrm{B}_{4} \mathrm{P}_{6}+$ $\mathrm{B}_{3} \mathrm{P}_{7}+\mathrm{B}_{2} \mathrm{P}_{8}+\mathrm{B}_{2} \mathrm{P}_{8}+\mathrm{B}_{1} \mathrm{P}_{9}$

11. Pemeliharaan pencegahan setiap sebelas bulan sekali,

$$
\begin{aligned}
\mathrm{B}_{11}= & \mathrm{N}\left(\mathrm{P}_{1}+\ldots+\mathrm{P}_{11}\right)+\mathrm{B}_{10} \mathrm{P}_{1}+\mathrm{B}_{9} \mathrm{P}_{2}+\mathrm{B}_{8} \mathrm{P}_{3}+\mathrm{B}_{7} \mathrm{P}_{4}+\mathrm{B}_{6} \mathrm{P}_{5}+\mathrm{B}_{4} \mathrm{P}_{7} \\
& +\mathrm{B}_{3} \mathrm{P}_{8}+\mathrm{B}_{2} \mathrm{P}_{9}+\mathrm{B}_{1} \mathrm{P}_{10}
\end{aligned}
$$

12. Pemeliharaan pencegahan setiap dua belas bulan sekali,

$$
\begin{aligned}
\mathrm{B}_{12}= & \mathrm{N}\left(\mathrm{P}_{1}+\ldots+\mathrm{P}_{12}\right)+\mathrm{B}_{11} \mathrm{P}_{1}+\mathrm{B}_{10} \mathrm{P}_{2}+\mathrm{B}_{9} \mathrm{P}_{3}+\mathrm{B}_{8} \mathrm{P}_{4}+\mathrm{B}_{7} \mathrm{P}_{5}+\mathrm{B}_{6} \mathrm{P}_{6} \\
& +\mathrm{B}_{5} \mathrm{P}_{7}+\mathrm{B}_{4} \mathrm{P}_{8}+\mathrm{B}_{3} \mathrm{P}_{9}+\mathrm{B}_{2} \mathrm{P}_{10}+\mathrm{B}_{1} \mathrm{P}_{11}
\end{aligned}
$$

2. Pemeliharaan Perbaikan

$$
C=\frac{(F) \cdot(R 1)}{R O . P}
$$

Dimana :

$\mathrm{C}=$ Biaya perbulan pemeliharaan

Bn $\quad=$ Ekspektasi jumlah kerusakan mesin dalam $\mathrm{n}$ bulan

$\mathrm{N} \quad=$ Jumlah mesin dalam kelompok 


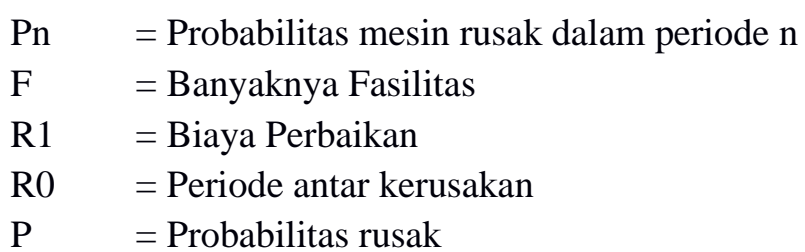

\section{Efisiensi biaya}

Pengukuran efisiensi dapat diukur dengan menggunakan deskriptif presentase. Rumus yang digunakan yaitu:

$$
\text { Efisiensi }=\frac{\text { Biaya Pemeliharaan yang di Peroleh }}{\text { Biaya Pemeliharaan Keseluruhan }} \times 100 \%
$$

Tabel 3

Kriteria Efisiensi

\begin{tabular}{cc}
\hline Presentase Kinerja & Kriteria \\
\hline $\mathbf{1 0 0 \%}$ keatas & Tidak efisien \\
$\mathbf{9 0 \% - 1 0 0 \%}$ & Kurang efisien \\
$\mathbf{8 0 \% - 9 0 \%}$ & Cukup efisien \\
$\mathbf{6 0 \% - 8 0 \%}$ & Efisien \\
Di bawah dari 60\% & Sangat efisien \\
\hline
\end{tabular}

Sumber: Mardiasmo (2004)

\section{HASIL DAN PEMBAHASAN}

Berikut mesin-mesin yang mengalami kerusakan di pabrik tahu Mitra Cemangi Kota Palu:

Tabel 4

Kerusakan Mesin-Mesin Produksi Pabrik Tahun 2018

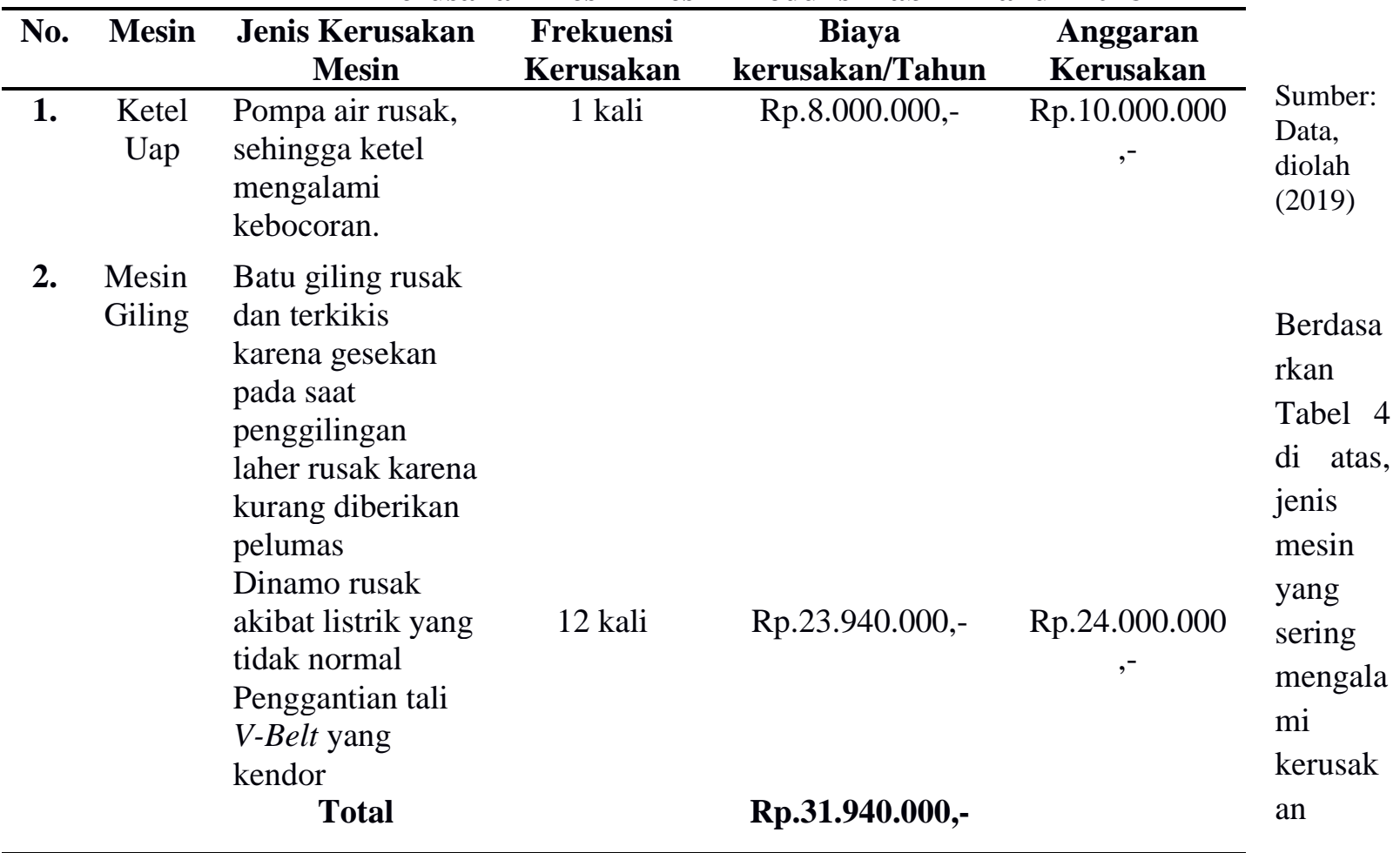


Vol. 7, No 3, Juli 2021, 248-257

adalah mesin giling dengan frekuensi kerusakan sebanyak 12 kali kerusakan selama tahun 2018 dan total biaya kerusakan sebesar Rp.23.940.000. kemudian untuk mesin ketel frekuensi kerusakan sebanyak 1 kali kerusakan selama tahun 2018 dengan total biaya kerusakan tahun 2018 sebesar Rp.8.000.000,--

\section{Sistem Pemeliharaan di Pabrik Tahu Mitra Cemangi}

Sistem pemeliharaan yang dilakukan di pabrik tahu Mitra Cemangi Kota Palu adalah sistem pemeliharaan korektif.

Tabel 5

Biaya Pemeliharaan Mesin Produksi Pabrik Tahu Mitra Cemangi Tahun 2018

\begin{tabular}{|c|c|c|c|c|}
\hline \multirow{2}{*}{ No. } & \multirow{2}{*}{ Mesin } & \multicolumn{2}{|c|}{ Biaya Pemeliharaan } & \multirow{2}{*}{$\begin{array}{c}\text { Frekuensi } \\
\text { Pemeliharaan }\end{array}$} \\
\hline & & DAP & GREASE & \\
\hline 1. & Ketel Uap & Rp.150.000,- & & 3 bulan sekali \\
\hline \multirow[t]{2}{*}{2.} & Mesin Giling & & Rp.20.000,- & 1 bulan sekali \\
\hline & Total & Rp.150.000,- & Rp.20.000,- & \\
\hline
\end{tabular}

Sumber: Data, diolah (2019)

Berdasarkan Tabel 5 di atas, maka dapat dilihat bahwa biaya pemeliharaan dap pada mesin ketel uap yaitu sebesar Rp.150.000, dan biaya pemeliharaan grease (pelumas) yaitu sebesar Rp.20.000.

Tabel 6

Periode Kerusakan Mesin Ketel Uap (2018)

\begin{tabular}{ccccc}
\hline No. & Periode & $\begin{array}{c}\text { Jumlah } \\
\text { Kerusakan }\end{array}$ & $\begin{array}{c}\text { Probabilitas } \\
(\mathbf{\%})\end{array}$ & $\begin{array}{c}\text { Probabilitas } \\
(\mathbf{\%}) \\
\text { Kumulatif }\end{array}$ \\
\hline $\mathbf{1 .}$ & Januari & 0 & 0,000 & 0 \\
$\mathbf{2 .}$ & Februari & 0 & 0,000 & 0 \\
$\mathbf{3 .}$ & Maret & 0 & 0,000 & 0 \\
$\mathbf{4 .}$ & April & 0 & 0,000 & 0 \\
$\mathbf{5 .}$ & Mei & 0 & 0,000 & 0 \\
$\mathbf{6 .}$ & Juni & 0 & 0,000 & 0 \\
$\mathbf{7 .}$ & Juli & 0 & 0,000 & 0 \\
$\mathbf{8 .}$ & Agustus & 0 & 0,000 & 0 \\
$\mathbf{9 .}$ & September & 1 & 1 & 1 \\
$\mathbf{1 0 .}$ & Oktober & 0 & 0,000 & 1 \\
$\mathbf{1 1 .}$ & November & 0 & 0,000 & 1 \\
$\mathbf{1 2 .}$ & Desember & 0 & 0,000 & $\mathbf{1}$ \\
& Jumlah & 1 & $\mathbf{1}$ &
\end{tabular}

Sumber: Data, data diolah (2019) 
Tabel 7

Periode Kerusakan Mesin Giling (2018)

\begin{tabular}{|c|c|c|c|c|c|c|c|c|c|c|c|c|c|c|}
\hline No. & Komponen & 1 & 2 & 3 & 4 & 5 & 6 & 7 & 8 & 9 & 10 & 11 & 12 & Jumlah \\
\hline \multirow[t]{3}{*}{1.} & Laher & 1 & 0 & 1 & 0 & 1 & 0 & 1 & 0 & 1 & 0 & 1 & 0 & 6 \\
\hline & $\begin{array}{c}\text { Probabilitas } \\
(\%)\end{array}$ & 0,17 & 0 & 0,17 & 0 & 0,17 & 0 & 0,17 & 0 & 0,17 & 0 & 0,17 & 0 & 1 \\
\hline & $\begin{array}{c}\text { Probabilitas } \\
\text { Kumulatif } \\
(\%)\end{array}$ & 0,17 & 0,17 & 0,33 & 0,33 & 0,5 & 0,5 & 0,67 & 0,67 & 0,83 & 0,83 & 1 & 1 & \\
\hline \multirow[t]{3}{*}{2.} & Dinamo & 0 & 0 & 1 & 0 & 0 & 0 & 1 & 0 & 0 & 0 & 1 & 0 & 3 \\
\hline & $\begin{array}{c}\text { Probabilitas } \\
(\%)\end{array}$ & 0 & 0 & 0,33 & 0 & 0 & 0 & 0,33 & 0 & 0 & 0 & 0,33 & 0 & 1 \\
\hline & $\begin{array}{c}\text { Probabilitas } \\
\text { Kumulatif } \\
(\%)\end{array}$ & 0 & 0 & 0,33 & 0,33 & 0,33 & 0,33 & 0,67 & 0,67 & 0,67 & 0,67 & 1 & 1 & \\
\hline \multirow[t]{3}{*}{3.} & $\begin{array}{l}\text { Batu } \\
\text { Giling }\end{array}$ & 0 & 0 & 0 & 0 & 1 & 0 & 0 & 0 & 0 & 0 & 0 & 1 & 2 \\
\hline & $\begin{array}{c}\text { Probabilitas } \\
(\%)\end{array}$ & 0 & 0 & 0 & 0 & 0,5 & 0 & 0 & 0 & 0 & 0 & 0 & 0,5 & 1 \\
\hline & $\begin{array}{c}\text { Probabilitas } \\
\text { Kumulatif } \\
(\%)\end{array}$ & 0 & 0 & 0 & 0 & 0,5 & 0,5 & 0,5 & 0,5 & 0,5 & 0,5 & 0,5 & 1 & \\
\hline \multirow[t]{4}{*}{4.} & V-Belt & 0 & 0 & 0 & 0 & 0 & 0 & 1 & 0 & 0 & 0 & 0 & 0 & 1 \\
\hline & $\begin{array}{c}\text { Probabilitas } \\
(\%)\end{array}$ & 0 & 0 & 0 & 0 & 0 & 0 & 1 & 0 & 0 & 0 & 0 & 0 & 1 \\
\hline & $\begin{array}{c}\text { Probabilitas } \\
\text { Kumulatif } \\
(\%)\end{array}$ & 0 & 0 & 0 & 0 & 0 & 0 & 1 & 1 & 1 & 1 & 1 & 1 & \\
\hline & Total & & & & & & & & & & & & & 12 \\
\hline
\end{tabular}

Sumber: Data, diolah (2019)

Berdasarkan Tabel 7 di atas maka dapat diperoleh bahwa tingkat probabilitas dari bulan Januari sampai Desember juga berfluktuasi. Hal ini, karena banyaknya frekuensi jumlah kerusakan pada setiap bulannya berbeda-beda.

Tabel 8

Anggaran Biaya Pemeliharaan Perusahaan dan Perbandingan Biaya Pemeliharaan Korektif dan Biaya Pemeliharaan Preventif Pertahun untuk Kedua Jenis Mesin

\begin{tabular}{|c|c|c|c|c|}
\hline Jenis Mesin & $\begin{array}{c}\text { Anggaran Biaya } \\
\text { Pemeliharaan } \\
\text { Perusahaan/ } \\
\text { Tahun }\end{array}$ & $\begin{array}{c}\text { Biaya } \\
\text { Pemeliharaan } \\
\text { Korektif/ } \\
\text { Tahun }\end{array}$ & $\begin{array}{c}\text { Biaya } \\
\text { Pemeliharaan } \\
\text { Preventif/ } \\
\text { Tahun }\end{array}$ & $\begin{array}{c}\text { Selisish } \\
\text { Biaya }\end{array}$ \\
\hline $\begin{array}{c}\text { Ketel Uap } \\
\text { Mesin }\end{array}$ & Rp.10.000.000 & Rp.1.000.000 & Rp.540.514 & Rp.459.486 \\
\hline $\begin{array}{c}\text { Giling } \\
\text { (laher) } \\
\text { (dinamo) } \\
\text { (batu giling) } \\
\text { (v-belt) }\end{array}$ & Rp.24.000.000 & $\begin{array}{c}\text { Rp. } 209.580 \\
\text { Rp.4.504.505 } \\
\text { Rp.800.000 } \\
\text { Rp.35.000 }\end{array}$ & $\begin{array}{c}\text { Rp.377.225 } \\
\text { Rp.4.452.883 } \\
\text { Rp.538.197 } \\
\text { Rp.84.927 }\end{array}$ & $\begin{array}{c}\text { Rp.167.645 } \\
\text { Rp.51.662 } \\
\text { Rp.261.803 } \\
\text { Rp.49.927 }\end{array}$ \\
\hline
\end{tabular}

Sumber: Data, diolah (2019)

Berdasarkan Tabel 8 di atas, diperoleh selisih biaya dari pemeliharaan preventif dan pemeliharaan korektif untuk mesin ketel yaitu sebesar Rp.459.486,- dan mesin giling (laher) Rp.167.645,- (dinamo) Rp.51.662,- (batu giling) Rp.261.803,- dan (v-belt) Rp.49.927,--

Ukuran Efisiensi Biaya 
1. Ketel Uap

Efisiensi $\frac{1.000 .000}{1.000 .000} \times 100 \%=100 \%$

Dari hasil perhitungan di atas diperoleh bahwa sistem pemeliharaan yang telah diterapkan di pabrik tahu Mitra Cemangi Kota Palu yaitu sebesar 100\%. Sehingga berdasarkan Tabel 3.2, apabila hasil perhitungan yang diperoleh berada di atas $60 \%$ tidak efisien.

2. Mesin Giling

\section{- Laher}

$$
\text { Efisiensi } \frac{209.580}{23.940 .00} \times 100 \%=0,87 \%
$$

- Dinamo

Efisiensi $\frac{4.504 .505}{23.940 .00} \times 100 \%=18,81 \%$

- Batu Giling

$$
\text { Efisiensi } \frac{800.000}{23.940 .000} \times 100 \%=3,34 \%
$$

- V-Belt

$$
\text { Efisiensi } \frac{35.000}{23.940 .000} \times 100 \%=0,14 \%
$$

Dari hasil perhitungan di atas diperoleh bahwa sistem pemeliharaan yang telah diterapkan di pabrik tahu Mitra Cemangi Kota Palu yaitu sebesar 0,87\% (laher), 18,81\% (dinamo), 3,34\% (batu giling) dan $0,14 \%$ (V-Belt). Sehingga berdasarkan Tabel 3.2, apabila hasil perhitungan yang diperoleh berada di bawah $60 \%$ sangat efisien.

\section{KESIMPULAN DAN SARAN}

\section{Kesimpulan}

Berdasarkan hasil analisis penelitian dan pembahasan yang telah di kemukakan dari bab-bab sebelumnya, maka peneliti dapat menarik kesimpulan bahwa:

- Sistem pemeliharaan yang dilaksanakan oleh pabrik tahu Mitra Cemangi Kota Palu yaitu pemeliharaan korektif, dengan pengukuran nilai efisiensi mesin ketel uap diperoleh hasil di atas $60 \%$ (tidak efisien), dan mesin giling pengukuran nilai efisiensi diperoleh hasil dibawah $60 \%$ (sangat efisien).

- Selisih biaya pemeliharaan preventif dan korektif untuk mesin ketel uap dan mesin giling sangat efisien menggunakan preventif daripada korektif.

\section{Saran}

1. Pabrik tahu Mitra Cemangi Kota Palu sebaiknya menggunakan sistem pemeliharaan preventif untuk kedua jenis mesin sehingga dapat mengefisiensikan biaya pemeliharaan yang dikeluarkan pada saat terjadi kerusakan.

2. Diharapkan kepada pihak pabrik tahu Mitra Cemangi Kota Palu perlu melakukan jadwal khusus terhadap pemeliharaan mesin dalam satu periode secara rutin agar dapat menghemat biaya, memperpanjang umur ekonomis mesin, dan mengurangi kerusakan pada mesin.

\section{REFERENSI}

Asngadi. (2011). Study Exploratory atas Faktor Penentu Konsumen Berkunjung di Mall Tatura Palu Sulawesi Tengah. Jurnal Aplikasi Manajemen. Vol. 9, No. 2, Maret 2011.

Assauri, Sofjan. (2008). Manajemen Produksi Dan Operasi. Edisi revisi. Lembaga Penerbit Fakultas Ekonomi Universitas Indonesia.

Ahyari, Agus. (2002). Pengendalian Produksi. Edisi IV cetakan kedua. Yogyakarta:Penerbit BPFE. 


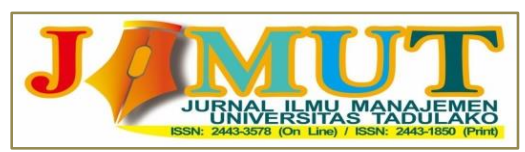

Vol. 7, No 3, Juli 2021, 248-257

Fahmi, irham. (2014). Manajemen Produksi Dan Operasi. Cetakan kedua. Bandung : Penerbit Alfabeta.

H.A, Rusdiana. (2014). Manajemen Operasi. Cetakan 1. Penerbit CV Pustaka Setia.

Handoko, Hani. 2014. Dasar-Dasar Manajemen Produksi dan Operasi. Edisi I cetakan kedelapanbelas. BPFE Yogyakarta.

Johns dan Harding (penyuntingan). (1996). Manajemen Operasi. Jakarta Pusat : Lembaga PPM.

Mardiasmo, (2004). Efisiensi dan Efektivitas. Penerbit Andy Jakarta.

Putra I, Husein Hi. Moh. Saleh, \& Asngadi. (2018). Analisis Pemeliharaan Mesin Produksi Pada PT. Haycarb Palu Mitra. Palu. Jurnal Ilmu Manajemen Universitas Tadulako. Vol. 5, No. 1, Januari 2019.

Prawirosentono, Suyadi. (2007) Manajemen Operasi (Operations Management). Analisis dan studi kasus. PT. Bumi Aksara.

Ruftyaz, Sefly. (2017). Analisis Pemeliharaan Mesin (Maintenance) Dalam Meningkatkan Efisiensi Biaya Pemeliharaan Pada Ciwawa Cake \& Bakery. Skripsi (S1), Fakultas Ekonomi dan Bisnis Unpas.

Render, dan Heizer. (2012). Manajemen Operasi. Edisi 9 buku 1. Penerbit Salemba Empat. 